\title{
THE JOURNAL of
}

\section{THE AUSTRALIAN MATHEMATIGAL SOCIETY}

\author{
VOLUME IX - PARTS 1, 2
}

\section{FEBRUARY 1969}

E. R. Love

S. J. Bernau

G. B. Preston

R. E. HARTWIG

A. M. Hasofer

W. D. WALLIS

G. M. KELLY

R. Padmanabhan

J. C. BURNS
Thomas MacFarland Cherry . . . . . . 1

On bare points. . . . . . . . . . . . 25

Matrix representations of inverse semigroups $\quad 29$

Toeplitz determinants and Szegö's formula. .

On the maximum of the geometric moving average. . . . . . . . . . 100

Factor ideals of some representation algebras 109 Monomorphisms, epimorphisms, and pullbacks. . . . . . . . . . . . . . . . 124

On single equational-axiom systems for Abelian groups. . . . . . . . . . 143

The iterated equation of generalized axially symmetric potential theory IV. Circle theorems. 
$\begin{array}{ll}\text { President: } & \text { C. S. DAvIS } \\ \text { Treasurer: } & \text { V. G. HART } \\ \text { Secretary: } & \text { W. PYE } \\ \text { Business Manager: } & \text { E. T. STELLER }\end{array}$

Membership subscriptions: Institutions: Other members:
University of Queensland University of Queensland Secondary Teachers' College, Victoria University of Queensland

$\$ 50$

$\$ 12$ (which may be reduced to $\$ 5$ for undergraduates and junior graduates)

Members of the Society receive copies of the Journal free.

Reciprocity agreements: Such agreements have been made with a number of other mathematical societies. Under the agreements members of the other societies who are not normally resident in Australia may join the Australian Mathematical Society at half the current rates. Such members receive copies of the Journal free.

Correspondence: All subscriptions and correspondence connected with accounts should be addressed to the Treasurer; all other correspondence connected with the Journal, except that concerned with the publication of papers, should be sent to the Business Manager. The address in. both cases is:

T'se Australian Mathematical Society,

Depertment of Mathematics,

University of Queensland,

St. Lucia, Queensland, 4067, Australia.

Applications for membership and other correspondence should be sent to the

Secretary, Australian Mathematical Society,

Secondary Teachers' College,

Swanston St., Parkville, Victoria 3053, Australia.

\section{THE JOURNAL}

Manuscripts (two copies) for publication should be sent either to the editor or to the appropriate associate editor at the address given in the list below. Manuscripts should be typewritten on good quality quarto sized white paper, the typing should be double spaced, on one side of the paper only, and there should be wide (at least $1 \frac{1}{2}$ inches) margins all round. Authors are asked to read the section "Preparation of Manuscripts" on the inside back cover.

Correspondence concerning the printing of papers after their acceptance for publication should be addressed to the assistant editor, M. A. B. Deakin, Department of Mathematics, Monash University, Clayton, Victoria $\mathbf{3 1 6 8 .}$

Authors receive 50 free offprints of their papers; additional offprints may be ordered at cost. Excessive costs incurred by the Society through corrections to or the withdrawal of articles may be charged to the authors concerned.

Each volume of the Journal consists of four parts. The price is $\$ 15$.

\section{Editor}

G. B. Preston, Department of Mathematics, Monash University, Clayton, Victoria 3168.

\section{Associate Editors}

\section{E. S. BARNES,}

Department of Mathematics, University of Adelaide,

Adelaide, South Australia 5001.

J. B. MILLER,

Department of Mathematics, Monash University, Clayton, Victoria 3168 .

\section{E. STRZEI.ecki,}

Department of Mathematics,

Monash University,

Clayton, Victoria 3168.

\section{P. D. Finch}

Department of Mathematics, Monash University,

Clayton, Victoria 3168.

A. F. Pillow,

Department of Mathematics, University of Queensland,

St. Lucia, Queensland 4067.

G. E. WALL,

Department of Mathematics (Pure Mathematics),

University of Sydney,

Sydney, N.S.W. 2006.
C. A. Hurst,

Department of Mathematical Physics,

University of Adelaide,

Adelaide,

South Australia 5001.

T. G. Room,

Department of Mathematics (Pure Mathematics),

University of Sydney.

Sydney, N.S.W. 2006.

K. C. Westrold,

Faculty of Science,

Monash University,

Clayton, Victoria 3168 